\title{
Evaluation of spermicidal and antiandrogenic activities of aqueous extract of Tinospora cordifolia (Willd.) stem
}

\author{
Sibi P Ittiavirah and P. K. Habeeb Rahman \\ Department of Pharmacology, University College of Pharmacy, Mahatma Gandhi University, Cheruvandoor, Ettumanoor \\ P. O., Kottayam, Kerala, India.
}

Accepted 14 August, 2013

\begin{abstract}
Control of population is very important in these years. A wide variety of synthetic contraceptive agents are available, but these cannot be used continuously due to their side effects. Thus the present study was undertaken to evaluate the antifertility effect of aqueous extract of Tinospora cordifolia stem studied in male Albino Wistar rats. Male rats were orally administered with aqueous extract of $T$. cordifolia stem (100 mg/kg of body weight/day, for 60 days) and effect of treatment on reproductive organ weights: fertility potential and sperm count were evaluated. The treatment caused decrease in weight of testis, epididymis and prostate. The treatment caused a significant reduction in average litter size, sperm count, number of viable and motile sperm. The administration of aqueous extract of $T$. cordifolia led to alteration in both the histoarchitecture of testis and epididymis. The results revealed that the aqueous extract of $T$. cordifolia stem has spermicidal and antiandrogenic activity.
\end{abstract}

Key words: Tinospora cordifolia, antifertility, antiandrogenic, spermicidal activity

\section{INTRODUCTION}

Nature has been a source of medicinal agents for thousands of years and an impressive number of modern drugs have been isolated from natural sources. World Health Organization suggested that effective, locally available plants be used as substitutes for drugs. Since the population explosion is a leading cause of poverty and pollution in developing countries, they created a population control programme, which includes studies of traditional medical practices. Fertility control is an issue of global and national public health concern. Current methods of contraceptive result in an unacceptable rate of unintended pregnancies. Approximately $50 \%$ of all pregnancies are unintended at conception; $50 \%$ occur in the $94 \%$ of sexually active couples who reported using some method of contraception (Henshaw, 1998). The only male-specific contraceptive methods currently available are withdrawal, condoms, and vasectomy. As concerns regarding side effects and inconvenience of these existing methods, which prevent their universal acceptance of the development of additional male methods of fertility control that can provide tremendous social and public health benefits.

Tinospora cordifolia known as Amrita (Guduchi) in Sanskrit, is widely used in folk and Ayurvedic systems of medicine. The term Amrita is attributed to its ability to impact youthfulness, vitality and longevity to the consumer. The large numbers of compounds have been isolated from the aerial parts and roots of $T$. cordifolia. Guduchi is widely used in Ayurvedic system of medicine "Rasayanas" for the immune system and the body resistance against infections. In modern medicine $T$. cordifolia used for the treatment of general weakness, fever, dyspepsia, dysentery, gonorrhoea, urinary diseases, viral hepatitis and anaemia more recently, the immunomodulatory properties, antineoplastic activities have been reported. 


\section{MATERIALS AND METHODS}

\section{Collection of plant material}

The fresh plant was collected from University College of Pharmacy, Cheruvandoor campus, Ettumanoor during the month of February. The same were botanically identified, confirmed and authenticated by Mr. Jobi Paul, Department of Environmental Science, MG University, Athirampuzha. The voucher number is 1104.

\section{Preparation of extract}

The fresh stems of $T$. cordifolia were washed with water and cut into small pieces, air dried for 10 days and the dried materials were powdered and subjected for extraction procedure. T. cordifolia stem powder was immersed in aqueous solution in a $5000 \mathrm{ml}$ flat bottom flask and was cold extracted for 7 days with occasional shaking and warming. At the end of the 7th day, the clear filtrate was obtained by filtering through a Buchner funnel. The filtrate was further concentrated by vacuum distillation, cooled, transferred into a Petri dish and dried in an oven at $60^{\circ} \mathrm{C}$ for a period of $5 \mathrm{~min}$. Finally, the aqueous extract was kept in desiccators for 15 days to remove the excessive moisture and was used for further studies (Kokate, 2000).

\section{Animals}

Healthy adult Wistar albino rats, weighing about 150 to $220 \mathrm{~g}$ obtained from the registered animal house of University College of Pharmacy, Cheruvandoor campus, MG University, Kottayam were used for the study. The study was approved by the Institutional Animal Ethical Committee, University College of Pharmacy, Cheruvandoor Campus [014/MPH/UCP/CVR/12].

\section{Experimental design}

The daily dose of the plant extract was freshly dissolved in normal saline and orally administered to each experimental animal every morning for 60 days. Each group contained 6 animals each.

\section{For antifertility activity}

Group I: Control rat received normal saline and Group II: Test received $100 \mathrm{mg} / \mathrm{kg}$ of aqueous extract of $T$. cordifolia stem.

\section{For antiandrogenic activity}

Group I: Control rat received normal saline, Group II: Test received $100 \mathrm{mg} / \mathrm{kg}$ of aqueous extract of T. cordifolia stem and Group III: Standard received $3 \mathrm{mg} / \mathrm{kg}$ of Flutamide.

\section{Antifertility activity}

After the termination of experiment all the male rats in each group were paired individually with two fertile females. Success of mating was confirmed by the presence of sperm in vaginal smear of mated rats. The average litter size was recorded (Revathy et al., 2010).

\section{Antiandrogenic activity}

The saline, test compound, standard are dissolved in sesame oil.
They received $0.9 \%$ saline, $100 \mathrm{mg} / \mathrm{kg}$ of $T$. cordifolia aqueous extract, and $3 \mathrm{mg} / \mathrm{kg}$ (Tinwell et al., 2007) of Flutamide, respectively. The treatment continued for 60 days, and on the 60th day, the animals are sacrificed. The weight of sex organs was compared with the weight of control group (Ravinthranath et al., 1996).

\section{Estimation of sperm motility and count}

The spermatozoa were obtained by making small cuts in caudate epididymis and vas deferens placed in $1 \mathrm{ml}$ of modified Krebs Ringer bicarbonate buffer $(\mathrm{pH} 7.4)$. The sperm suspension was evaluated for sperm count, percent motility. The sperm count was determined under a Neubauer heamocytometer.

\section{Statistical analysis}

Statistical analysis was performed by using 'Graph pad prism 6' software by one way analysis of variance (ANOVA) followed by Dunnet's multiple comparison tests. All data were expressed as Mean \pm standard error of mean (SEM), $\mathrm{P}<0.05$ was considered as statistically significant.

\section{RESULTS}

The percentage yield of the extract was calculated to be $6.6 \% \mathrm{w} / \mathrm{w}$.

\section{Fertility test}

Control as well as aqueous extract treated rats mated with female rats. All the female rats that mated with the control male rats delivered litters, whereas only two of these 12 female rats that mated with test male rats delivered litters.

\section{Effect of treatment on weight of testis}

Weight of testis in test group was significantly reduced when compared with the control group, weight reduction was more marked in standard, that is, Flutamide treated group (Figure 1).

\section{Effect on weight of epididymis}

Weight of epididymis in test group was significantly reduced when compared with the control group, weight reduction was more marked in standard, that is, flutamide treated group (Figure 2).

\section{Effect on weight of prostate}

Weight of prostate $(\mathrm{mg})$ in test group was significantly 


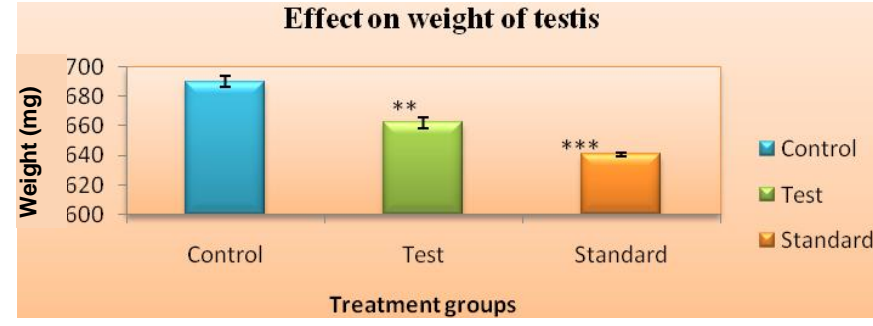

Figure 1. Effect of treatment on weight of testis.

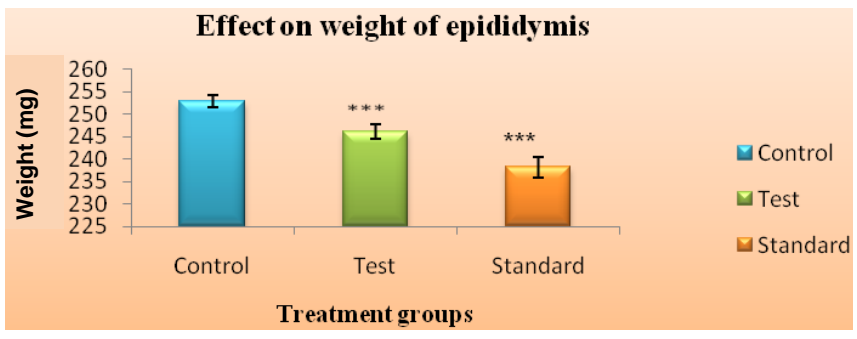

Figure 2. Effect of treatment on weight of epididymis

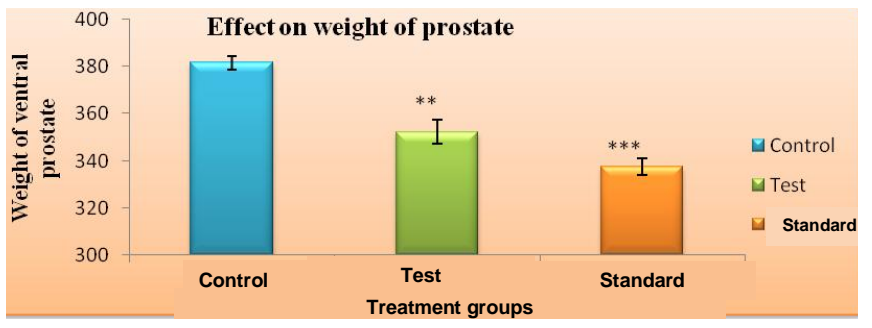

Figure 3. Effect of treatment on weight of prostate.

Table 1. Effect of treatment on sperm count (Mean \pm SEM).

\begin{tabular}{lc}
\hline Treatment group & No. of sperm in $\mathbf{1 0} / \mathbf{m l}$ \\
\hline Control & $29.17 \pm 3.51$ \\
Test & $14.17 \pm 2.85$ \\
Standard & $9.33 \pm 2.35$ \\
\hline
\end{tabular}

Table 2. Effect of treatment on sperm motility (Mean \pm SEM).

\begin{tabular}{lc}
\hline Treatment & No. of motile sperms in $\mathbf{1 0} / \mathbf{m l}$ \\
\hline Control & $19.83 \pm 1.80$ \\
Test & $3.5 \pm 0.90$ \\
Standard & $2.02 \pm 0.32$ \\
\hline
\end{tabular}

reduced when compared with the control group, weight reduction was more marked in standard, that is, Flutamide treated group (Figure 3).

\section{Effect of treatment on sperm count}

The sperm count in the treated group was significantly reduced when compared with the control. The reduction was more marked in standard treated group (Table 1).

\section{Effect of treatment on sperm motility}

The sperm count in the treated group was significantly reduced when compared with the control. The reduction was more marked in standard treated group (Table 2).

\section{Effect of treatment on histology of testis}

Effect of treatment caused degenerative changes in histology of testis and epididymis (Figures 4 to 7 ).

The study of cross sections of controls epididymis revealed that the majority of the tubules of ductus epididymis were compactly arranged, but both in the test and standard groups, degeneration of tubules were seen, and the degeneration more marked in standard group.

\section{DISCUSSION}

The decrease in fertility potential that was reported in male rats treated with aqueous extract has been attributed to decreased sperm count, impairment in sperm motility and viability. The treated group shows significant reduction in litter size and most of the rats do not produce any litters. The findings of the present study indicated that the aqueous extract of $T$. cordifolia could significantly alter the fertility potential of male rats. The anti-fertility activity was evaluated on the basis of the effect of extract on litter size, spermatogenesis, and effect on organ weight and histo-morphological examination. The group which received aqueous extract for 60 days showed marked decrease in the epididymal sperm count. The decrease in the sperm may be due to the hormonal activity of the extract. Spermatogenesis, an sequential process of transformation of primary spermatogonia through a series of stages into the round spermatids which involves cell division through mitosis as well as meiosis (Krester et al., 1994).

The sperm have two principal attributes, motility and fertilizing ability which is prerequisite for fertilization; any negative impact on motility would seriously affect the fertilizing ability (Akbarsha et al., 2000). The sperm sample contains more than $20 \%$ of abnormal spermatozoa consider to be more infertile. Motility of the sperm is due to flagellar beat which in turn is dependent on microtubular apparatus of the flagella (Eddy et al., 2004). Sperms while leaving testis are not motile but show motility during their epididymal transit. The epididymis contribute to initiate motility by providing unique 

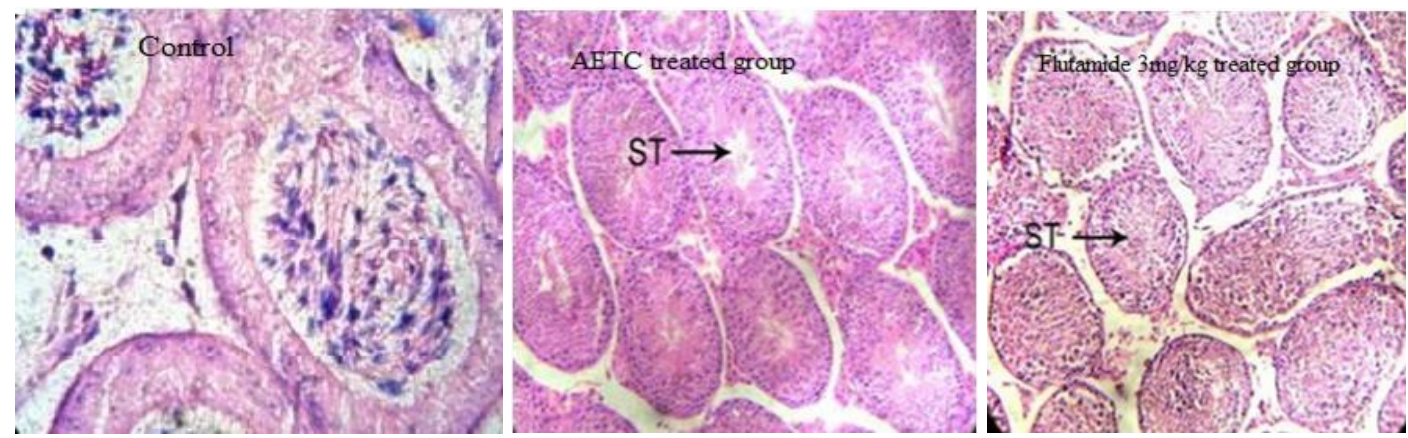

Figure 4. Effect of treatment on histology of three segments of epididymis.
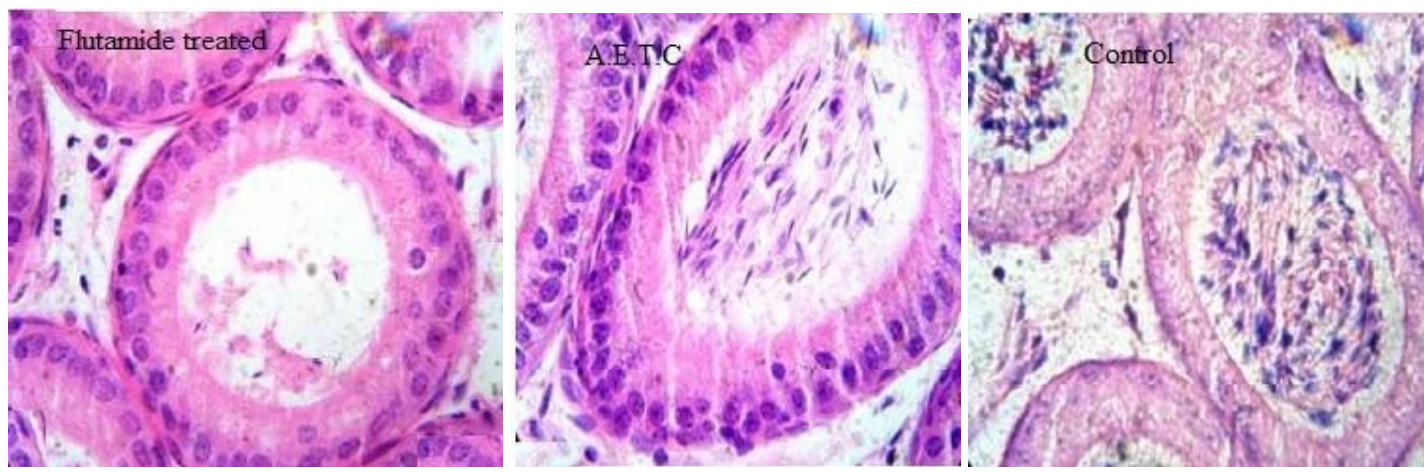

Figure 5. Histology of caput-epididymis.
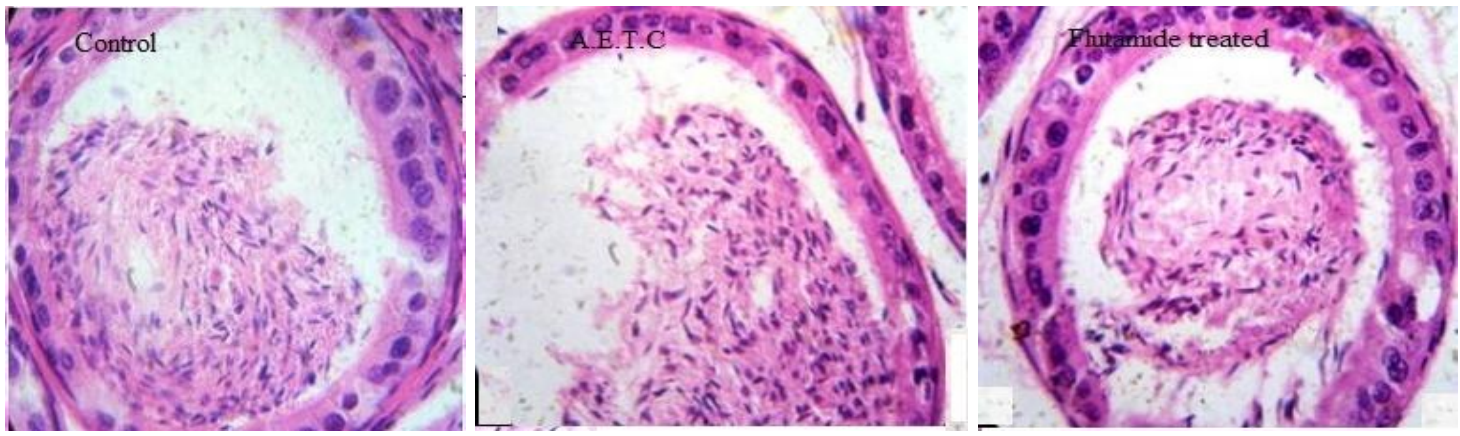

Figure 6. Histology of cauda-epididymis.

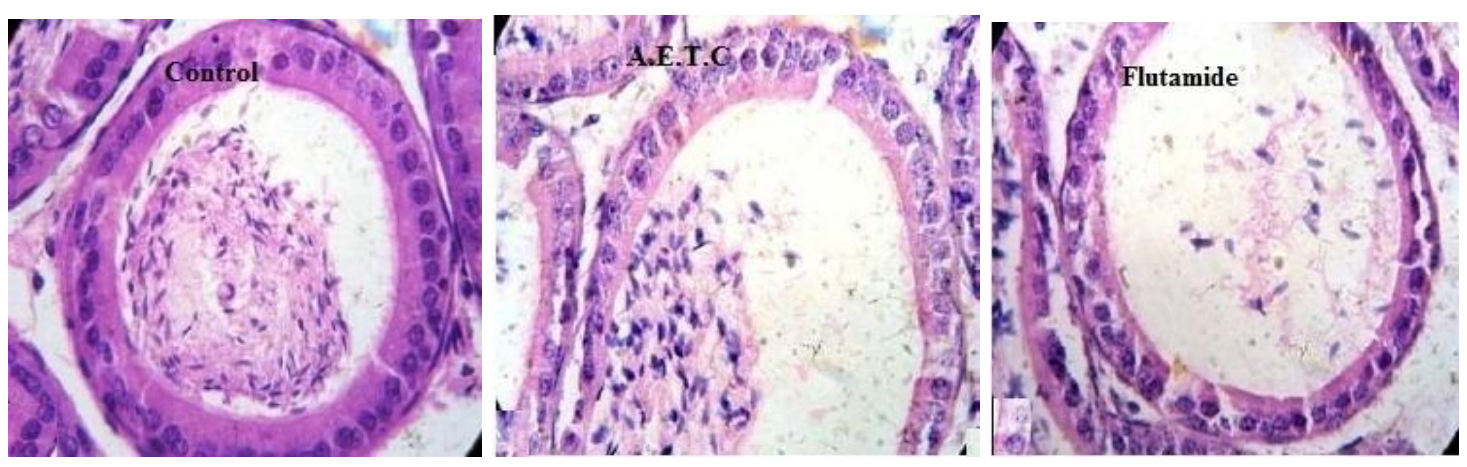

Figure 7. Histology of corpus-epididymis. 
microenvironment along the length for the sperm to resist and secreting protein and some important compound which in one way or other are concerned with the initiation of sperm motility. The changes essentially involve addition of new proteins, removal of existing proteins and modification of existing proteins. Particularly, much is known about the sperm motility initiation protein, acrosomal stabilization protein, etc (Revathy et al., 2010). Such maturation, leading to initiation of motility, depends upon the modifications sperm undergo with reference to the surface proteins and small molecular weight compounds (Guyton and Hall, 2006). Hence, the sperm collected from the cauda epididymis was not at all motile, thus clearly indicating the interaction of treatment with the maturation of sperm in epididymis, a large portion of existing sperms was unviable and several of the sperm had undergone structural abnormalities. Therefore, from this point of view, is due to aqueous extract of $T$. cordifolia.

The decrease in sperm count due to inhibition of spermatogenesis is confirmed by histomorphological examination of the testis and epididymis. Histopathological examination showed greater reduction in the testicular spermatozoa than epididymal sperma-tozoa. This might be due to the marked decrease in the diameter of the seminiferous tubules, accounting for the gross decrease in the testicular size. This indicates that the extract may have effect on pituitary gonadotropin.

The weight reduction of sex organs in treated group indicating a significant anti-androgenic activity. For the normal growth of accessory sex organs androgen is a must. The reduced sperm count, decreased sperm motility and viability also associated with this anti-androgenic activity. It has been shown that androgens are essential for survival and motility of spermatozoa in the rat epididymis, cauda region appears to be the most favorable site. It is likely that any contraceptive agent that affects sperm motility would influence spermatozoa indirectly through disruption of epididymal epithelial cell function or act directly on the spermatozoa by affecting their enzymes. A significant increase in the abnormal sperm count and inhibition of sperm motility in treated rats suggests that this extract target is within the internal milieu of the epididymis or alterations in the epididymal epithelium in the cauda epididymis. The comparison of body weight also reveals a significant effect of the treatment on the hormonal milieu. The body weight before the treatment is almost similar in both of control, test and standard groups. After treatment there was a significant reduction in the body weight of both standard and test treated groups. This weight reduction was more marked in standard anti-androgen (Flutamide) treated group, and this reduced body weight in extract treated group shows a similar antiandrogenic activity of aqueous extract.

The antifertility activity of the extract is significant, the activity maybe due to the presence of phenolics and flavonoids. The present study revealed that the administration of aqueous extract of $T$. cordifolia in a dose of $100 \mathrm{mg} / \mathrm{kg}$ body weight caused a marked reduction in litter size, sperm count, sperm motility and sperm viability. Treatment group shows a significant reduction in body weight, testis, epididiymis and prostate weights. These effects of treatment on the sex organs clearly suggest the antiandrogenic activity of the extract. The histology of organs confirmed the antiandrogenic activity. Hence, it is concluded that this impairment may have caused the effects produced by the treatment on the spermatogenesis which in turn results in decreased sperm count. Hence, the study revealed that treatment of aqueous extract of $T$. cordifolia $(100 \mathrm{mg} / \mathrm{kg})$ for 60 days significantly reduced fertility profile of male rats. Thus, further studies are needed to isolate these potential constituents of the $T$. cordifolia for specific male antifertility activity.

\section{ACKNOWLEDGEMENT}

The authors wish to use this opportunity to express their deep sense of gratitude and indebtedness to Dr. Sibi P. I., M Pharm, Ph.D., Assistant Professor, Head, Department of Pharmacology, University College of Pharmacy, Kottayam for his inspiring guidance, timely invaluable suggestions, co-operation and help during the course of the project.

\section{REFERENCES}

Guyton CA, Hall JE (2006). Text book of Medical Physiology. 11th ed. Philadelphia Elselvier, Inc. pp. 999-1000

Henshaw SK (1998). Unintended pregnancy in the United States. Fam. Plann. Perspect. 30:24-29

Kokate CK, Purohit AP, Gokhale SB (eds) (2005). Pharmacognosy.4th ed, Pune, Niraliprakashan, New Delhi, India pp 107-109.

Ravinthranath N, Papadopoulos V, Brooker G, Dym M (1996). Rat Sertoli calcium response to basement membrane and folliclestimulating hormone. Biol. Reprod. 54:130-137

Revathy P, Vani B, Sarathchandiran I, Kadalmani B, Shyam KP, Palnive K (2010). Reproductive toxicity of Capparis aphylla (Roth.) in male albino rats. Int. J. Pharm. Biomed. Res. 1(3):102-112

Tinwell H, Santini CF, Rouquie D, Belluco S, Elies L, Pallen C, Bars B (2007). Evaluation of the antiandrogenic effects of Flutamide, dde, and linuron in the weanling rat assay using organ weight, histopathological, and proteomic approaches. Toxicol. Sci. 100(1):5465. 